14

\title{
Возможный механизм рецепции инфракрасного излучения: роль температурного фактора
}

\author{
() И.Л. Ячнев, В.А. Пеннияйнен, С.А. Подзорова, И.В. Рогачевский, Б.В. Крылов
}

Институт физиологии им. И.П. Павлова РАН, 199034 Санкт-Петербург, Россия

e-mail: krylov@infran.ru

(Поступило в Редакцию 30 мая 2017 г.)

\begin{abstract}
Исследована роль температурного фактора в механизме рецепции низкоинтенсивного инфракрасного (ИК) излучения мембраной сенсорного нейрона при воздействии излучения $\mathrm{CO}_{2}$-лазера $(\lambda=10.6 \mu \mathrm{m})$. Методом органотипической культуры эмбриональной ткани проведены измерения и оценки температуры монослоя из сенсорных ганглиев при различных плотностях энергии излучения. Исследована реакция ткани на воздействие низкоинтенсивного ИК излучения. Установлено, что ингибирование роста ткани в области малых плотностей энергии излучения $\left(10^{-14}-10^{-10} \mathrm{~J} / \mathrm{cm}^{2}\right)$ сменяется ростом ткани в области $10^{-7}-10^{-4} \mathrm{~J} / \mathrm{cm}^{2}$ и последующим ингибированием в области $10^{-1}-6 \mathrm{~J} / \mathrm{cm}^{2}$. Специфическая реакция на нетепловое излучение статистически достоверно зарегистрирована при плотности мощности излучения, равной $3 \cdot 10^{-10} \mathrm{~J} / \mathrm{cm}^{2}$. Рассмотрены механизмы воздействия излучения на эмбриональную ткань. Показано, что специфический механизм рецепции низкоинтенсивного ИК излучения, длина волны которого составляет $10.6 \mu \mathrm{m}$, может быть активирован в области плотности энергий излучения от $10^{-14}$ до $10^{-10} \mathrm{~J} / \mathrm{cm}^{2}$.
\end{abstract}

DOI: 10.21883/JTF.2018.02.45426.2366

\section{Введение}

Передача информации в нервной системе осуществляется с помощью кода нервных импульсов, частотные характеристики которого несут сведения о раздражителях, падающих на рецепторы живого организма. В ноцицептивной системе центральную роль в кодировании болевых сигналов играют медленные натриевые каналы $\mathrm{Na}_{V}$ 1.8. Повышение их функциональной активности ведет к увеличению частоты импульсной активности ноцицепторов, что на организменном уровне проявляется в усилении ощущения боли. С другой стороны, любое воздействие, которое способно специфически снизить функциональную активность этих мембранных ионных каналов, должно приводить к анальгетическому эффекту. Важнейшим свойством каналов $\mathrm{Na}_{V} 1.8$ оказалась их связь с „соседними“ мембранными структурами. Такой структурой в мембране ноцицептивного нейрона является $\mathrm{Na}^{+}, \mathrm{K}^{+}$-АТФаза, выполняющая здесь не только свою основную насосную функцию, но и функцию трансдуктора сигнала [1]. Эта трансдукторная функция натриевого насоса была обнаружена также и в клетках кардиомиоцитов [2]. Физиологическая роль белка-трансдуктора заключается в усилении молекулярного сигнала, идущего от мембранного рецептора, а также в передаче возбуждения на эффекторную исполнительную структуру, которой в нашем случае служит канал $\mathrm{Na}_{V} 1.8$. Очевидно, что наличие этого механизма в возбудимой мембране делает возможным активировать трансдукторопосредованную модуляцию ионных каналов. Это предположение нашло свое подтверждение при использовании нами фармакологического подхода. Применение чрезвычайно низких (эндогенных) концентраций уабаи- на, специфического блокатора $\mathrm{Na}^{+}, \mathrm{K}^{+}$-АТФазы, приводит к анальгетическому эффекту благодаря снижению потенциалочувствительности каналов $\mathrm{Na}_{V} 1.8$ [3]. Ранее нами также было показано, что к анальгетическому эффекту приводит и воздействие на мембрану сенсорного нейрона низкоинтенсивного ИК излучения $\mathrm{CO}_{2}$-лазера. И.Л. Ячнев и соавторы [4] предложили возможный механизм рецепции излучения $\mathrm{CO}_{2}$-лазера мембраной ноцицептивного нейрона. Наиболее важным процессом этого механизма является модуляция трансдукторной функции $\mathrm{Na}^{+}, \mathrm{K}^{+}$-АТФазы. Факт существования анальгетического эффекта, вызываемого действием низкоинтенсивного ИК излучения, позволяет по-новому подойти к разработке эффективного и безопасного физиотерапевтического метода купирования хронической боли. Для этого необходимо отделить температурную компоненту падающего на мембрану излучения, которая неспецифически повышает частоту повторных ответов мембраны ноцицептивного нейрона, что, в свою очередь, ведет к усилению боли, от специфического нетеплового воздействия ИК излучения, влияющего только на трансдукторную функцию $\mathrm{Na}^{+}, \mathrm{K}^{+}$-АТФазы, специфическая активация которой приводит к лечебному анальгетическому эффекту. Решению этой задачи посвящена настоящая работа.

\section{Методика исследования}

Для выяснения влияния температуры на рост нейритов сенсорных ганглиев использовали метод органотипической культуры ткани, подробно описанный в нашей предыдущей работе [3]. Исследования проведены на эксплантатах 10-12-дневных куриных эмбрионов, 


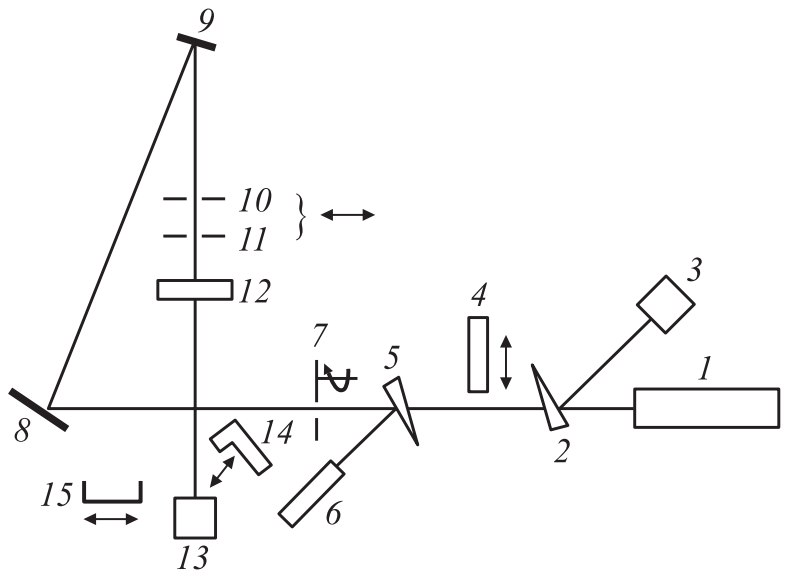

Pис. 1. Оптическая схема установки: $1-\mathrm{CO}_{2}$-лазер, $2,5-$ оптические клины, 3,13 - измерители мощности излучения, 4 - механический экран, 6 - диодный лазер, 7 - дисковый ослабитель, 8,9 - зеркала, 10,11 - диафрагмы, 12 поглощающая ячейка, 14 - термометр, 15 - чашка Петри.

культивируемых в чашках Петри на подложках из коллагена в $\mathrm{CO}_{2}$-инкубаторе (Sanyo, Япония) в течение трех суток при $36.5^{\circ} \mathrm{C}$ и $5 \% \mathrm{CO}_{2}$. Питательная среда содержала $45 \%$ раствора Хенкса, $40 \%$ среды Игла с добавлением инсулина $(0.5$ units $/ \mathrm{ml})$, глюкозы $(0.6 \%)$, глютамина $(2 \mathrm{mM})$, гентамицина (100 units $/ \mathrm{ml}), 5 \%$ куриного эмбрионального экстракта и $10 \%$ фетальной сыворотки коровы. Контрольными служили эксплантаты, культивируемые только в условиях питательной среды. Для количественной оценки роста эксплантатов применяли морфометрический метод. Индекс площади (ИП) рассчитывали как отношение площади зоны роста эксплантата к исходной центральной площади, где находятся немигрирующие клетки. Контрольное значение ИП принимали за 100\%. Статистический анализ проводили с помощью программы STATISTICA 8.0 с применением $t$-критерия Стьюдента. Для визуализации объектов использовали микроскоп Axio Observer Z1 (Carl Zeiss, Германия). Полученные изображения анализировали с использованием программ ImageJ и ZEN_2012. Работа выполнена на оборудовании ЦКП „Конфокальная микроскопия“ Института физиологии им. И.П. Павлова РАН.

Оптическая схема экспериментальной установки представлена на рис. 1. Источником излучения являлся $\mathrm{CO}_{2}$-лазер 1. Мощность излучения измерялась в пучке, отраженном от передней поверхности оптического клина 2, измерителем мощности излучения 3 типа ИМО-2Н. Для визуализации положения луча $\mathrm{CO}_{2}$-лазера в пространстве использовался полупроводниковый лазер с длиной волны $0.635 \mu \mathrm{m} 6$, луч которого совмещался с лучом $\mathrm{CO}_{2}$-лазера при помощи оптического клина 5 . По видимому лучу полупроводникового лазера юстировались все последующие оптические элементы схемы. Механическим экраном 4 определялось время облучения исследуемого образца. Диафрагмы 10,11 юстировоч- ными подвижками выставляли соосно с помощью отвеса для обеспечения нормального падения пропущенного через них лазерного луча на поглощающую ячейку 12 . Поглощающую ячейку 12 использовали для ослабления излучения. Нижним окном ячейки являлся клин из $\mathrm{ZnSe}$ диаметром $12 \mathrm{~cm}$, верхним окном - плоскопараллельная пластинка из $\mathrm{BaF}_{2}$. Зазор между окнами ячейки определялся кольцом из проволоки калиброванного диаметра. В качестве поглощающей среды использовали дистиллированную воду. Водой заполняли область внутри кольца. При наложении на кольцо верхнего окна ячейки избыток воды выдавливался через разрыв в кольце. Нижнее окно ячейки устанавливали горизонтально, используя два уровня, которые располагали на поверхности окна перпендикулярно друг другу. Сочетание находящегося в горизонтальной плоскости поглощающего слоя воды и вертикально падающего на него пучка излучения обеспечивало соответствующую диаметру проволоки кольца толщину поглощающей среды. Перед облучением исследуемых эксплантатов проводили измерения мощности излучения $\mathrm{CO}_{2}$-лазера одновременно измерителями мощности 3 и 13 при выведенных из области пучка диафрагмах и отсутствии в поглощающей ячейке воды. При этом относительной величине мощности излучения, регистрируемой измерителем мощности 3 , сопоставлялась величина мощности излучения на выходе из ячейки. В последующих опытах с облучением эксплантатов для оценки мощности излучения на образце использовались данные измерителя мощности 3 с учетом потерь мощности в поглощающем слое воды. Бесконтактный термометр 14 располагался на подвижке, при помощи которой на время измерения температуры он размещался над образцом на расстоянии, обеспечивающем измерение температуры только с площади, равной площади поверхности монослоя эксплантатов. Точность измерения температуры бесконтактным термометром была проверена путем сопоставления его показаний с показаниями ртутного термометра при одновременном измерении температуры воды в области $34-42^{\circ} \mathrm{C}$. На основании результатов проведенной калибровки систематическая погрешность бесконтактного термометра была принята равной $0.1^{\circ} \mathrm{C}$. Температуру монослоя из эксплантатов, имевшего диаметр $5 \mathrm{~mm}$, измеряли до и сразу после его облучения. Во время облучения в чашке Петри отсутствовала питательная среда. Время облучения составляло $3 \mathrm{~min}$.

\section{Результаты и их обсуждение}

Через трое суток культивирования эмбриональной нервной ткани в контрольных и экспериментальных эксплантатах сенсорных ганглиев формируются две зоны: центральная, состоящая из немигрирующих дифференцирующихся нейробластов, и периферическая, так называемая зона роста. В зоне роста преобладает рост нейритов (отростков нервных клеток), в менышей 
степени здесь мигрируют и пролиферируют фибробластоподобные клетки и глия. Количественная оценка действия излучения основана на измерении роста нейритов с помощью определения индекса площади. ИП является чрезвычайно чувствительным параметром, позволяющим оценивать степень внешнего воздействия на нервные клетки. При плотности энергии излучения $10^{-14} \mathrm{~J} / \mathrm{cm}^{2}$ влияние ИК излучения на рост нейритов сенсорных ганглиев отсутствовало, ИП практически не отличался от контрольного значения. Излучение, плотность энергии которого составляла $10^{-10} \mathrm{~J} / \mathrm{cm}^{2}$, вызывало достоверное ингибирование роста нейритов. ИП экспериментальных эксплантатов был в среднем на $30 \pm 5 \%(n=20)$ ниже контрольного значения. При плотности энергии излучения $10^{-7} \mathrm{~J} / \mathrm{cm}^{2}$ наблюдали ингибирование роста нейритов. ИП был ниже контрольных значений на $20 \pm 8 \%$. Излучение $\mathrm{CO}_{2}$-лазера при плотности энергии излучения $10^{-1} \mathrm{~J} / \mathrm{cm}^{2}$ вызывало статистически недостоверную стимуляцию роста нейритов. При этом ИП экспериментальных эксплантатов был на $20 \pm 5 \%$ выше по сравнению с контролем. Дальнейшее увеличение плотности энергии вызывало статистически достоверное ингибирование роста нейритов. Так, при плотности энергии ИК излучения $6 \mathrm{~J} / \mathrm{cm}^{2}$ ИП был на $45 \pm 7 \%(n=20)$ ниже контрольного значения (рис. 2).

Для выяснения роли температурного фактора в механизме взаимодействия ИК излучения с мембраной нервной клетки была проведена отдельная серия экспериментов. Десять измерений при плотности энергии излучения $10^{-1} \mathrm{~J} / \mathrm{cm}^{2}$ позволили получить следующие величины температур монослоя из сенсорных ганглиев. До воздействия излучения его температура равнялась $T_{0}=(25.1 \pm 0.2)^{\circ} \mathrm{C}$, а после облучения $T=(25.5 \pm 0.1)^{\circ} \mathrm{C}$. При этом величина изменения температуры монослоя составила $\Delta T=(0.3 \pm 0.1)^{\circ} \mathrm{C}$.

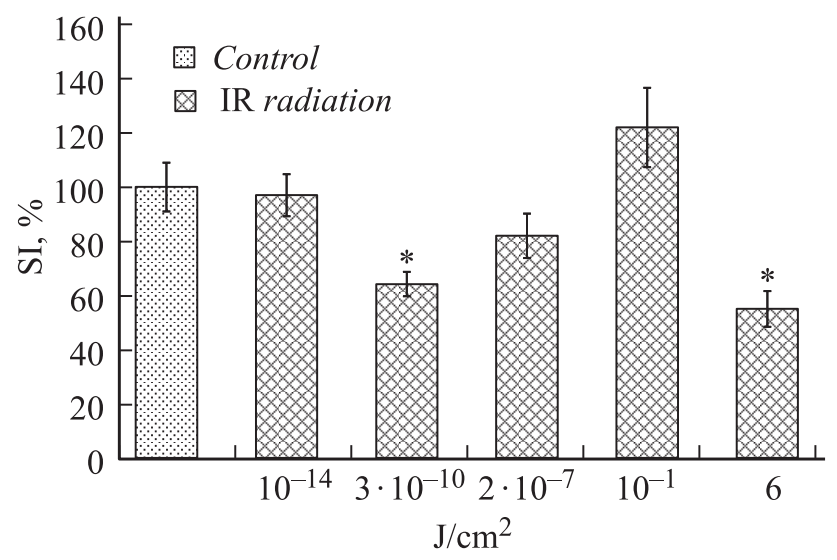

Рис. 2. Изменение индекса площади эксплантатов сенсорных ганглиев 10-12-дневных куриных эмбрионов при воздействии ИК излучения (третьи сутки культивирования). По оси ординат - индекс площади эксплантатов (SI, \%). ${ }^{*}$ - различия достоверны относительно контрольных эксплантатов, $p<0.05$.
Приращение температуры монослоя из сенсорных ганглиев

\begin{tabular}{l|c|c|c|c}
\hline$q, \mathrm{~J} / \mathrm{cm}^{2}$ & $3 \cdot 10^{-10}$ & $2 \cdot 10^{-7}$ & $10^{-1}$ & 6 \\
\hline ИП, \% & 62 & 82 & 120 & 55 \\
$T_{0},{ }^{\circ} \mathrm{C}$ & - & - & $25.2 \pm 0.2$ & - \\
$T,{ }^{\circ} \mathrm{C}$ & - & - & $25.5 \pm 0.1$ & - \\
$\Delta T_{0},{ }^{\circ} \mathrm{C}$ & $9 \cdot 10^{-10}$ & $6 \cdot 10^{-7}$ & $0.3 \pm 0.1$ & 18
\end{tabular}

Примечание $q-$ плотность излучения, $\Delta T-$ приращение температуры, ИП - индекс площади, $T_{0}$ - начальная температура эксплантата, $T$ - температура эксплантата после облучения.

Ранее на основании данных, полученных при просвечивании монослоя из сенсорных ганглиев, расположенного на прозрачной для излучения $\mathrm{CO}_{2}$-лазера пластинке из $\mathrm{ZnSe}$, был определен коэффициент поглощения нервной ткани $\mu=69 \mathrm{~cm}^{-1}$ [5]. Знание $\mu$ и толщины эксплантата $L=3.2 \cdot 10^{-2} \mathrm{~cm}$ позволяет определить величину поглощенной нервной тканью энергии излучения $\left(Q_{\text {absorp }}\right)$ и, используя выражение

$$
\Delta T=Q_{\text {absorp }} / \rho \cdot c p \cdot V,
$$

где $\rho$ - плотность, $c p-$ удельная теплоемкость, $V-$ объем образца, найти величину произведения $(\rho \cdot c p)$. Величина $\rho \cdot c p$, являющаяся постоянной при различных плотностях энергии излучения, использовалась для оценки приращения температуры монослоя из сенсорных ганглиев в других областях плотностей энергии излучения. Результаты такой оценки $\Delta T$ при плотностях энергии $3 \cdot 10^{-10}, 2 \cdot 10^{-7}$ и $6 \mathrm{~J} / \mathrm{cm}^{2}$ и величина $\Delta T$, измеренная при плотности энергии излучения $0.1 \mathrm{~J} / \mathrm{cm}^{2}$, представлены в таблице.

Полученные данные свидетельствуют о том, что в диапазоне плотностей энергии излучения $\mathrm{CO}_{2}$-лазера $10^{-12}-10^{-4} \mathrm{~J} / \mathrm{cm}^{2}$ излучение является низкоинтенсивным, его воздействие не приводит к таким изменениям температуры, которые могут быть восприняты нервной клеткой. В этой области плотности энергии излучения зависимость изменения роста нервной ткани обусловлена взаимодействием нетеплового ИК излучения с мембраной нервной клетки (рис. 2).

В области плотностей энергии $10^{-12}-10^{-10} \mathrm{~J} / \mathrm{cm}^{2} \mathrm{pe}-$ цепция излучения происходит благодаря поглощению излучения молекулами АТФ, находящимися в сайте их гидролиза на $\mathrm{Na}^{+}, \mathrm{K}^{+}$-АТФазе. Фрагментом молекулы АТФ, поглощающим излучение, является терминальный фосфатный остаток $\mathrm{PO}_{4}^{3-}$, имеющий частоту деформационного колебания $(\mathrm{O}-\mathrm{P}-\mathrm{O})_{\gamma}$, близкую к частоте излучения [5]. Колебательная энергия фосфатного остатка может быть передана $\mathrm{Na}^{+}, \mathrm{K}^{+}$-АТФазе без потерь, связанных с внутримолекулярной релаксацией колебательной энергии, при наличии у взаимодействующих молекул близких по энергии колебательных уровней. Передаваемая $\mathrm{Na}^{+}, \mathrm{K}^{+}$-АТФазе энергия излучения вызывает изменение ее конформации, отличное от конформационных переходов, осуществляющихся в процессе функционирования $\mathrm{Na}^{+}, \mathrm{K}^{+}$-АТФазы как ионного насоса, 
что приводит к специфическому запуску ее трансдукторной функции, которая обусловливает наличие спадающей левой (первой) ветви зависимости изменения роста нервной ткани. Роль $\mathrm{Na}^{+}, \mathrm{K}^{+}$-АТФазы как трансдуктора заключается в усилении сигнала - энергии излучения. Увеличение энергии в колебательной моде $\mathrm{Na}^{+}, \mathrm{K}^{+}$-АТФазы, аккумулирующей энергию излучения, может происходить в результате быстрой релаксации свободной энергии гидролиза по колебательным модам $\mathrm{Na}^{+}, \mathrm{K}^{+}$-АТФазы.

Следующая (вторая) ветвь зависимости роста нервной ткани в области плотностей энергий $10^{-10}-10^{-4} \mathrm{~J} / \mathrm{cm}^{2}$, отражающая увеличение ИП, является следствием процессов, стимулирующих рост нейритов, что может быть связано с активацией насосной функции $\mathrm{Na}^{+}, \mathrm{K}^{+}$-АТФазы. При увеличении плотности энергии излучения скорость аккумуляции энергии излучения в соответствующей колебательной моде $\mathrm{Na}^{+}, \mathrm{K}^{+}$-АТФазы может превышать скорость ее использования для активации трансдукторной функции. В этом случае избыток энергии излучения в результате быстрого межмодового взаимодействия будет перераспределяться между колебательными модами $\mathrm{Na}^{+}, \mathrm{K}^{+}$-АТФазы. При передаче какой-то доли этой энергии колебательной моде $\mathrm{Na}^{+}, \mathrm{K}^{+}$-АТФазы, в которую поступает свободная энергия гидролиза АТФ, восстанавливается ее конформационное преобразование, обеспечивающее функционирования $\mathrm{Na}^{+}, \mathrm{K}^{+}$-АТФазы как ионного насоса. С увеличением энергии, обеспечивающей работу ионного насоса, возрастает его активность, что должно проявляться в усилении роста нейритов.

Дальнейшее повышение плотности энергии излучения от $10^{-4}$ до $10^{-1} \mathrm{~J} / \mathrm{cm}^{2}$ сопровождается увеличением температуры монослоя из сенсорных ганглиев от 0.01 до $0.3^{\circ} \mathrm{C}$. Это такая область температур, в которой может проявляться влияние температурного фактора на терморецепторы нервной ткани. Нижний предел этой области соответствует порогу их температурной чувствительности [6]. Третья (правая) спадающая ветвь изменения роста нервной ткани (рис. 2) может быть результатом доминирующего действия тех тепловых процессов, которые при плотности энергии излучения, превышающей $6 \mathrm{~J} / \mathrm{cm}^{2}$ и вызывающей увеличение температуры монослоя сенсорных ганглиев больше, чем на $18^{\circ} \mathrm{C}$, могут приводить к ингибированию роста нервных клеток.

В результате проведенных исследований установлена область плотности энергии излучения $\mathrm{CO}_{2}$-лазера, в которой воздействие излучения на мембрану нервных клеток является нетепловым. Полученные данные позволяют заключить, что статистически достоверно мембрана нервных клеток теплокровных животных способна специфически воспринимать воздействие низкоинтенсивного ИК излучения, длина волны которого составляет $10.6 \mu \mathrm{m}$, при плотности мощности излучения, равной $3 \cdot 10^{-10} \mathrm{~J} / \mathrm{cm}^{2}$. Этот эффект обусловлен активацией трансдукторной функции $\mathrm{Na}^{+}, \mathrm{K}^{+}$-АТФазы, что является ключевым процессом механизма рецепции низкоинтенсивного ИК излучения.

Работа выполнена в рамках Программы фундаментальных научных исследований государственных академий наук (ГП14, тема № 64.1).

\section{Список литературы}

[1] Крылов Б.В., Дербенев А.В., Подзорова С.А., Людыно М.И., Кузьмин А.В., Изварина Н.Л. // Рос. физиол. журн. 1999. T. 85. № 2. C. 225-236.

[2] Xie Z., Askari A. // Eur. J. Biochem. 2002. Vol. 269. N 10. P. 2434-2439.

[3] Lopatina E.V., Yachnev I.L., Penniyaynen V.A., Plakhova V.B., Podzorova S.A., Shelykh T.N., Rogachevsky I.V., Butkevich I.P., Mikhailenko V.A., Kipenko A.V., Krylov B.V. // Medicinal Chemistry. 2012. Vol. 8. N 1. P. 3-39.

[4] Yachnev I.L., Plakhova V.B., Podzorova S.A., Shelykh T.N., Rogachevsky I.V., Krylov B.V. // Medicinal Chemistry. 2012. Vol. 8. N 1. P. 14-21.

[5] Ячнев И.Л., Шелых Т.Н., Подзорова С.А., Рогачевский И.В., Крылов Б.В., Плахова В.Б. // ЖТФ. 2016. Т. 86. Вып. 6. C. $132-136$.

[6] Stevens J.C., Choo K.K. // Somatosensory end motor research. 1998. Vol. 15. N 1. P. 13-28. 